\title{
Experimental investigation and optimization of wall deflection and material removal rate in milling thin-wall parts
}

\author{
Gururaj Bolar ${ }^{1, *}$ and Shrikrishna Nandkishor Joshi ${ }^{2}$ \\ ${ }^{1}$ Department of Mechanical and Manufacturing Engineering, Manipal Institute of Technology, Manipal Academy of Higher \\ Education, Manipal, 576 104, Karnataka, India \\ 2 Department of Mechanical Engineering, Indian Institute of Technology Guwahati, Guwahati, 781 039, Assam, India
}

Received: 27 November 2020 / Accepted: 10 June 2021

\begin{abstract}
The selection of optimal process parameters is essential while machining thin-wall parts since it influences the quality of the product and affects productivity. Dimensional accuracy affects the product quality, whereas the material removal rate alters the process productivity. Therefore, the study investigated the effect of tool diameter, feed per tooth, axial and radial depth of cut on wall deflection, and material removal rate. The selected process parameters were found to significantly influence the in-process deflection and thickness deviation due to the generation of unfavorable cutting forces. Further, an increase in the material removal rate resulted in chatter, thus adversely affecting the surface quality during the final stages of machining. Considering the conflicting nature of the two performance measures, Non-dominated Sorting Genetic Algorithm-II was adopted to solve the multi-objective optimization problem. The developed model could predict the optimal combination of process variables needed to lower the in-process wall deflection and maintain a superior surface finish while maintaining a steady material removal rate.
\end{abstract}

Keywords: Thin-wall milling / part deflection / material removal rate / aluminum alloy 2024-T351 / surface roughness / multi-objective optimization / NSGA-II

\section{Introduction}

Improving fuel efficiency is of prime importance in aircraft industries. For this purpose, modern aircraft manufacturers incorporate thin monolithic structures designed to have high rigidity with minimal thickness of $1-2.5 \mathrm{~mm}[1]$. These monolithic thin-wall structures are fabricated by removing approximately $90-95 \%$ of the material from the blanks using the machining operation [2]. Since a large volume of material needs to be machined, the thin-wall machining process productivity needs to be significantly improved by increasing the Material Removal Rate (MRR). But, maximization of MRR can adversely impact the dimensional accuracy and surface quality during the final stages of production. Also, the dynamic properties of low rigidity parts are significantly altered by the rate of material removal [3]. Therefore, the determination of the optimal process parameters is essential to effectively machine the low rigidity parts without affecting the surface and dimensional quality.

\footnotetext{
* e-mail: gururaj.bolar@manipal.edu
}

Numerous research work on machining aspects of thinwall has been carried out and reported. Ning et al. [4] analyzed the thin-wall deformation mechanism using the Finite Element Method (FEM), and a numerically controlled compensation strategy was suggested to improve the process efficiency and precision. Wang and Hsu [5] worked on obtaining a mirror surface finish during one-pass milling of aluminum 6061-T6 alloy while maximizing MRR by optimizing the process using a sequential neural network approximation method. Few experimental studies coupled with analytical work on deflection and vibration during high-speed thin-wall milling were conducted by Herranz et al. [6]. The curvature of the thin-walled workpiece was found to influence cutting forces and surface errors [7]. The relationship between structural modes and chatter stability was analyzed, and a dynamic stability model was developed for the thin-wall machining process [8]. Experiments were carried out by Han et al. [9] to determine the thin-wall deflection. The effects of wall thickness and different grades of aluminum alloy on deflection were studied. It was concluded that the strength of various grades of the same material had little effect on the thin-wall deflection. FEM-based simulations 
were used to study the effect of heat treatment, feeding direction, and tool inclination angle on the thin-wall surface accuracy [10]. A 3-D structural FEM model was developed to analyze the impact of wall constraints on thinwall deflection $[11,12]$. The work was further extended to include the thermal aspects, and a detailed study on cutting forces, machining stresses, chip morphology, and the cutting temperature was undertaken.

Bolar et al. [13] investigated the influence of process variables on the surface quality and machining forces during the thin-wall machining operation. The analysis revealed that tool diameter was a crucial parameter that influenced the cutting forces and surface finish while machining thin-wall parts. Particle swarm optimization (PSO) and the FEM were used to optimize thin-wall machining fixture and the cutting parameters simultaneously for minimizing the elastic deformation [14]. An analytical model for compensating the deflection errors induced due to real-time milling forces was developed by $\mathrm{Du}$ et al. [15]. Li and Zhu [16] developed an error compensation model to minimize deformation during five-axis blade milling. Sol et al. [17] experimentally evaluated the impact of cutting speed, feed rate on the cutting forces, and part quality during the thin-wall machining operation. In the due process, cutting forces were reduced by about $20 \%$, while the thickness deviation was reduced by $40 \%$, thus improving the product quality. $\mathrm{Qu}$ et al. [18], by considering the cutting force, surface roughness, and MRR, optimized the thin-wall machining process using a Non-dominated Sorting Genetic Algorithm (NSGA-II). Vukman et al. [19] took the fuzzy logic approach to determine the surface roughness during the thin-wall machining process. It was reported that the zigzag tool path resulted in a poor surface finish, while the true spiral tool path provided the best surface finish. A study on the influence of end mill helix angle showed that the low helix tool of $35^{\circ}$ developed built-up edges, which lowered the surface quality. In contrast, the tool with a high helix angle of $55^{\circ}$ provided a superior surface finish [20]. A penalty cost function approach was used to optimize the MRR while machining thin-wall structures [21]. Recently, Cheng et al. [22] utilized Artificial Bee Colony (ABC) algorithm to minimize the surface roughness and wall deformation and determine the optimum process variables.

The reported studies have discussed the influence of process parameters and tool geometry parameters on cutting forces, wall deflection, and surface roughness. Researchers have also developed analytical and FEM models to predict and compensate for the wall deflection and form errors. However, while machining thin parts, it is essential to produce components within the allowable dimensional tolerances while decreasing the production cost through the maximization of MRR. Scant literature has been reported on the influence of process parameters on the MRR and the wall deflection during the thin-wall machining process. Therefore, an effort was made to scrutinize the impact of tool diameter, feed, axial, and radial depth of cut on wall deflection, and MRR during finish machining of thin-walls. Full factorial experiments were conducted on aluminum alloy 2024-T351 work material using solid carbide end mills. Analysis of variance

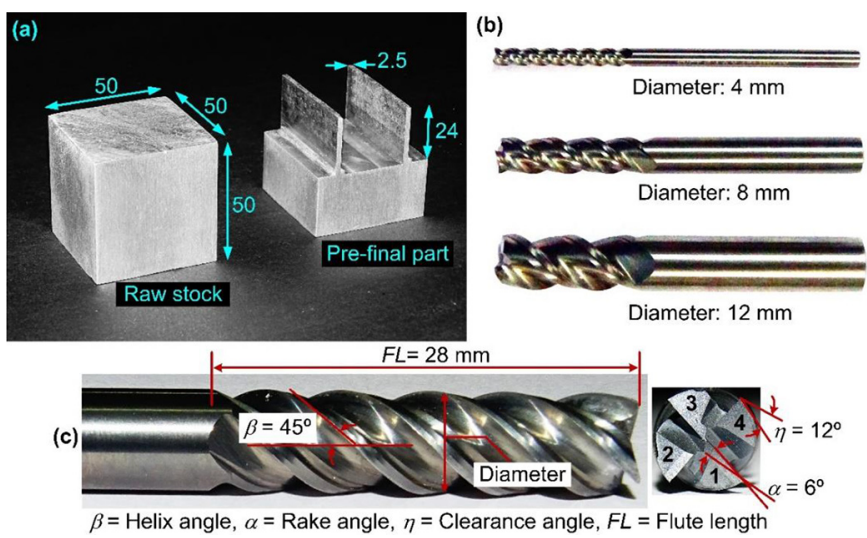

Fig. 1. (a) Thin-wall workpiece with dimensions; (b) Solid carbide end mills used during the experiments; (c) Tool geometry parameters.

(ANOVA) was used to identify the crucial factors which influence the part deflection and MRR. Mathematical models were developed using regression techniques. Finally, NSGA-II was adopted to solve the multi-objective problem and determine the optimum combinations of process parameters.

\section{Materials and method}

Aerospace-grade aluminum alloy 2024-T351 was used as workpiece material. The workpiece was machined to its pre-final shape, as shown in Figure 1a. During the experiments, the thickness of the thin-wall was reduced to $1.25 \mathrm{~mm}$. Machining of the thin-wall components was carried under environmentally friendly dry-cutting conditions. Flat solid carbide end mills were used in the research and are presented in Figure 1b. Related cutting tool geometry parameters are shown in Figure 1c. A vertical machining center (VMC) having three-axis ( $P M K$ $M C-3 / 400)$ with Siemens Sinumerik CNC controller was used to conduct the machining tests. Linear Variable Differential Transformer (LVDT) (Solartron $A X / 5 / S$ ) was used to measure the wall deflection (see Fig. 2). Additionally, a coordinate measuring machine (Carl Zeiss Vista) was used to measure the magnitude of form error at the top end of the machined thin-walls. The MRR was computed by calculating the machining time and actual volume of material removed.

A full factorial study was planned and analyzed using Response Surface Methodology. Tool diameter $\left(d_{i}\right)$, feed per tooth $\left(f_{z}\right)$, radial $\left(r_{d}\right)$, and axial depth of cut $\left(a_{d}\right)$ were considered independent variables. Spindle speed $\left(n_{s}\right)$ and other tool parameters viz. tool helix, the number of teeth were kept constant. A total of $81\left(3^{4}\right)$ experiments were executed, considering the four milling parameters at three levels listed in Table 1. Further, quadratic regression models were developed to study the performance characteristics considered in the present study. ANOVA was performed on the developed regression models to evaluate the process responses and determine the significant input parameters. Statistical analysis (Sum of Squares, F-test, 


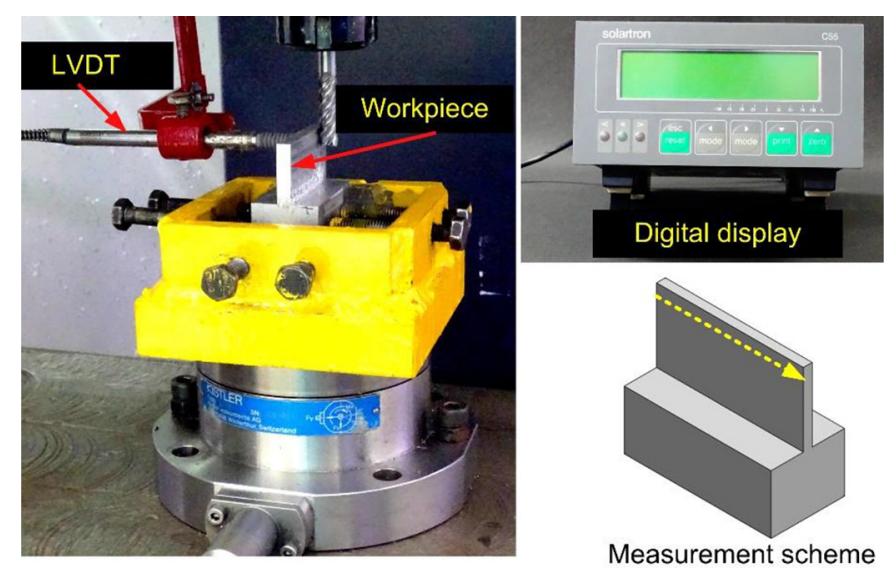

Fig. 2. Wall deflection measurements using LVDT.

Table 1. Experimental milling parameters.

\begin{tabular}{llll}
\hline Milling parameters & Level 1 & Level 2 & Level 3 \\
\hline$f_{z}(\mathrm{~mm} / \mathrm{z})$ & 0.02 & 0.04 & 0.06 \\
$d_{i}(\mathrm{~mm})$ & 4 & 8 & 12 \\
$a_{d}(\mathrm{~mm})$ & 8 & 12 & 24 \\
$r_{d}(\mathrm{~mm})$ & 0.3125 & 0.625 & 1.25 \\
\hline
\end{tabular}

and $p$-value) was carried out to verify the model adequacy. Moreover, optimum parameter settings considering the two objectives, viz. maximization of MRR, and minimization of wall deflection, were determined using NSGA-II. Finally, milling experiments were conducted to verify the optimized results. The systematic methodology used in the proposed study is depicted in Figure 3.

\section{Results and discussion}

Thin-wall machining experiments were conducted according to the designed plan, and the measured responses are tabulated in Table A1 (Appendix A).

\subsection{Analysis of wall deflection}

The dimensional accuracy of machined low rigidity parts is affected by the in-process wall deflection. Therefore, a quadratic regression model of wall deflection $\left(D_{f}\right)$ is formulated considering the significant terms. The statistical significance of the process variables is evaluated by considering a 95\% confidence level. The regression equation for the wall deflection in terms of actual values is given by:

$$
\text { See equation (1) below. }
$$

Additionally, ANOVA is used to evaluate the impact of significant model terms and verify the validity of the fitted model. The results of the ANOVA for the developed quadratic model are listed in Table 2. Main effect factors $d_{i}$, $f_{z}, a_{d}, r_{d}$, the quadratic effect of $r_{d}^{2}$, the interaction effect of $d_{i}$ and $r_{d}$, the interaction effect of $f_{z}$ and $a_{d}$, the interaction effect of $f_{z}$ and $r_{d}$, the interaction effect of $a_{d}$ and $r_{d}$ are significant model terms. The value of $F=100.81, p<0.0001$ and $R^{2}=0.930$ indicates the significance of the developed regression model for wall deflection. Predicted $R^{2}$ and adjusted $R^{2}$ values of 0.908 and 0.921 suggest that the developed model is adequate. For a developed model, an adequate precision of more than four is recommended to indicate that the signal is noise-free. In the study, an adequate precision ratio of 42.98 is an indicator of the good response prediction accuracy of the model. The above discussion justifies the sufficiency of the wall deflection prediction model for a given set of input parameters.

A normal probability plot of studentized residuals for wall deflection presented in Figure 4a shows that the residuals are normally distributed, verifying the normality test. The distribution of the actual values relatively near the predicted value-line indicates that the model is satisfactory (see Fig. 4b).

The perturbation plot between coded units of variable factors and wall deflection shows the effect of independent variables (see Fig. 5a). The deflection of a thin-wall workpiece increases with $d_{i}$. As $d_{i}$ value increases, the forces acting on the thin-wall increase due to an increase in the cutting area resulting in higher deflections. An increase in the magnitude of wall deflection with $f_{z}$ value is also attributed to the cutting force value. As $f_{z}$ value increases, the chip load increases, which in turn increases the force value. The rise in the magnitude of cutting force increases the magnitude of wall deflection. Further, as $a_{d}$ increases, the length of work-tool contact increases, which increases the milling force values. This, in turn, escalates the wall deflection. Similarly, as $r_{d}$ increases, tool immersion into the workpiece increases, which causes the cutting force to rise, thus resulting in excessive wall deflection. Figure $5 \mathrm{~b}-\mathrm{e}$ exhibits the effect of interaction between the process parameters. The interactive plots indicate the increase in the magnitude of wall deflection with the increase in $f_{z}, a_{d}$, and $r_{d}$. In contrast, there is a reduction in the magnitude of wall deflection as $d_{i}$ increases. It is always desired in-process deflection of the wall is lower to prevent any dimensional inaccuracy. From the plots, it is evident that lower wall deflection can be obtained by using a $4 \mathrm{~mm}$ diameter end mill and maintaining the values of $f_{z}, a_{d}$, and $r_{d}$ at their lowest.

The ANOVA indicates that $a_{d}, r_{d}$, and their interaction significantly influence the wall deflection with contributions of $20.31 \%, 55.82 \%$, and $12.56 \%$, respectively. Figure 6 shows the side views of thin-wall specimens machined by considering $a_{d}$ values of $12 \mathrm{~mm}$ to $24 \mathrm{~mm}$ using an $8 \mathrm{~mm}$ diameter tool. Due to the wall deflection, the material

$$
D_{f}=\left[\begin{array}{l}
0.264-8.531 e^{-3} \cdot d_{i}-1.197 \cdot f_{z}-9.828 e^{-3} \cdot a_{d}-0.570 \cdot r_{d}+1.419 e^{-2} \cdot d_{i} \cdot r_{d} \\
+0.101 \cdot f_{z} \cdot a_{d}+2.376 \cdot f_{z} \cdot r_{d}+2.010 e^{-2} \cdot a_{d} \cdot r_{d}+0.216 \cdot r_{d}^{2}
\end{array}\right]
$$




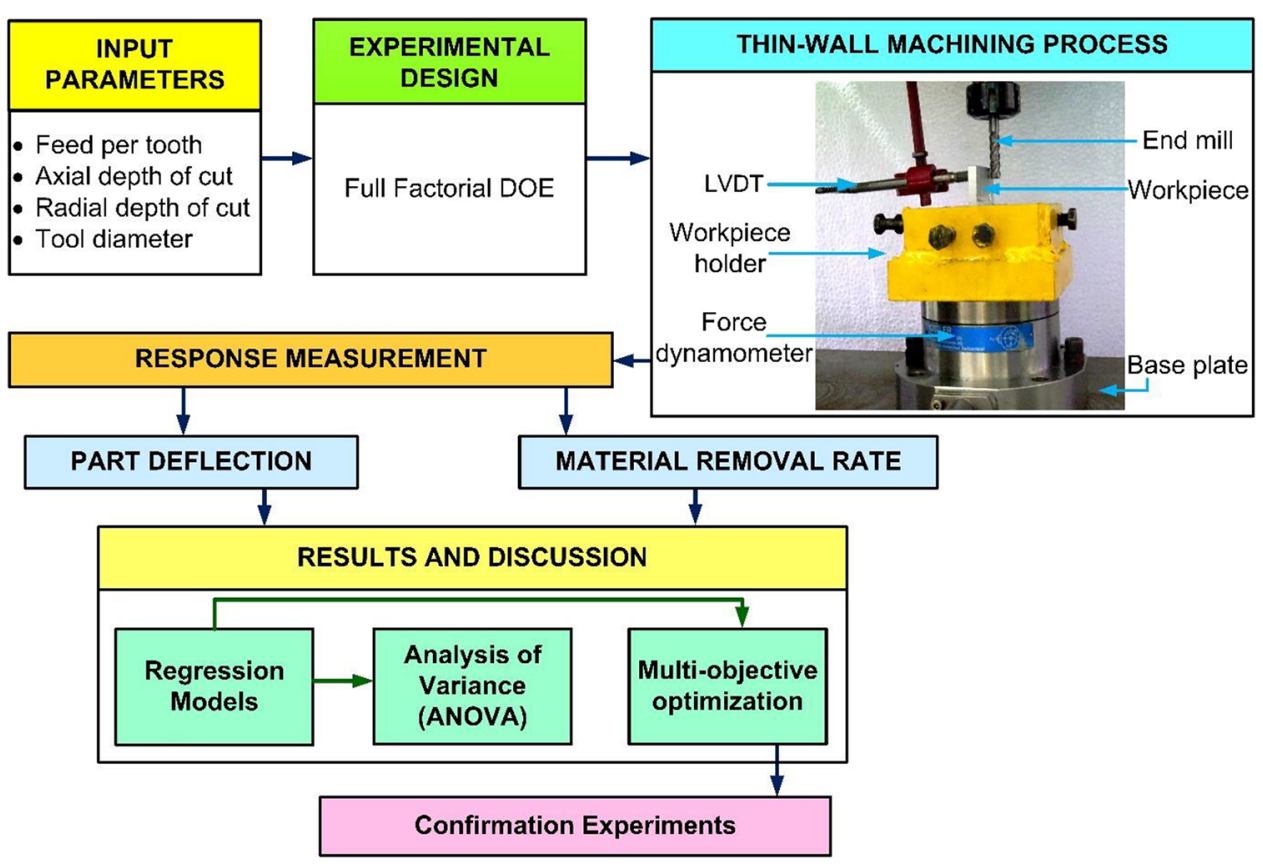

Fig. 3. Overview of the experimental work.

Table 2. ANOVA for the quadratic model of wall deflection (After elimination).

\begin{tabular}{llllll}
\hline Source & Sum of squares & DF & Mean square & $F$-value & $p$-value \\
\hline Model & 1.41 & 9 & 0.1566 & 100.81 & $<0.0001$ \\
$d_{i}$ & 0.0049 & 1 & 0.0049 & 3.16 & 0.0800 \\
$f_{z}$ & 0.0976 & 1 & 0.0976 & 62.83 & $<0.0001$ \\
$a_{d}$ & 0.3277 & 1 & 0.3277 & 211.01 & $<0.0001$ \\
$r_{d}$ & 0.9006 & 1 & 0.9006 & 579.88 & $<0.0001$ \\
$d_{i}^{* * r_{d}}$ & 0.0226 & 1 & 0.0226 & 14.56 & 0.0003 \\
$f_{z^{*} a_{d}}$ & 0.0098 & 1 & 0.0098 & 6.29 & 0.0145 \\
$f_{z^{*}}$ & 0.0168 & 1 & 0.0168 & 10.84 & 0.0016 \\
$a_{d} * r_{d}$ & 0.2027 & 1 & 0.2027 & 130.54 & $<0.0001$ \\
$r_{d}^{2}$ & 0.0306 & 1 & 0.0306 & 19.71 & $<0.0001$ \\
Residual & 0.11 & 68 & 0.0016 & & \\
Cor. Total & 1.51 & 77 & & & \\
\hline
\end{tabular}

remains cut at the top as compared to that at the base, thereby resulting in a form error. Closer inspection reveals that the form error at the free end of the wall machined increases as $a_{d}$ value increases. Figure 7 shows the side view of thin-wall workpieces machined using $12 \mathrm{~mm}$ diameter tools when $a_{d}$ is maintained at $24 \mathrm{~mm}$, and $r_{d}$ is varied from $0.625 \mathrm{~mm}$ to $1.25 \mathrm{~mm}$. There is a substantial rise in form error with the increase in $r_{d}$ value.

\subsection{Analysis of the material removal rate}

In the thin-wall machining process, achieving high productivity is of equal importance in addition to good surface quality and dimensional accuracy. The MRR can be enhanced by increasing the spindle speed, feed rate, axial and radial depth of cut $[23,24]$. But, the dynamic properties of the thin-wall workpiece are significantly altered by the material removal during the machining process. Thin-wall components are susceptible to dimensional error and chatter due to wall deflection under severe processing conditions. Therefore, a quadratic regression model of MRR is formulated considering the significant terms. The statistical significance of the process variables is evaluated by considering a $95 \%$ confidence level. The regression equation for MRR in terms of actual values is given by: 


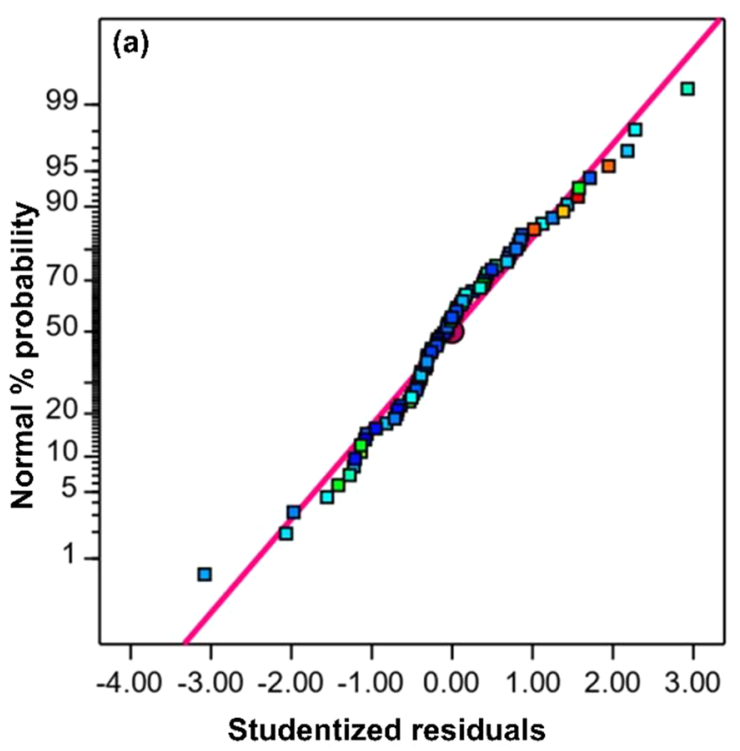

Fig. 4. (a) Normal probability plot of studentized residuals.

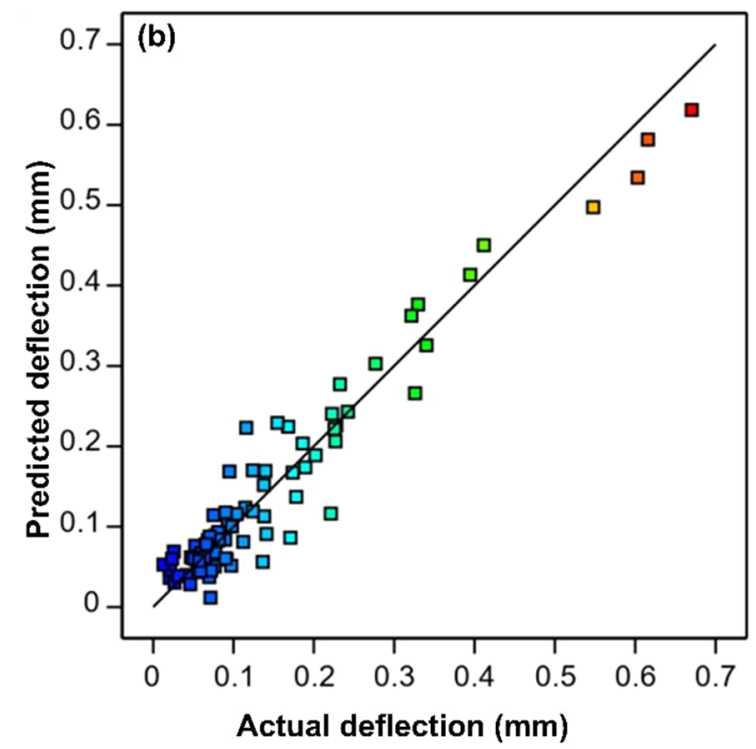

(b) Plot of actual vs. predicted response for wall deflection.

\section{See equation (2) below.}

Furthermore, ANOVA is used to evaluate the impact of significant model terms and verify the validity of the fitted model. Table 3 presents the results of ANOVA for the MRR regression model after the elimination of the nonsignificant terms. The F-value of 531.85 implies that the model is significant. The $R^{2}$ of 0.984 indicates that the developed model is significant. Predicted $R^{2}$ and adjusted $R^{2}$ values of 0.976 and 0.983 indicate that the developed model is adequate. Also, an adequate precision ratio of 102.25 indicates the good response prediction accuracy of the model. The above discussion justifies the sufficiency of the MRR regression model for a given set of input parameters. Main effect factors $d_{i}, f_{z}, a_{d}, r_{d}$, the quadratic effect of $r_{d}^{2}$, the interaction effect of $f_{z}$ and $a_{d}$, the interaction effect of $f_{z}$ and $r_{d}$, the interaction effect of $a_{d}$ and $r_{d}$ are significant model terms. A normal probability plot of studentized residuals for MRR presented in Figure 8a shows that the residuals are normally distributed, verifying the normality test. The distribution of the actual values relatively near the predicted value-line indicates that the model is satisfactory (see Fig. 8b).

From the perturbation plot shown in Figure 9a, it is evident that the increase in $f_{z}, a_{d}$, and $r_{d}$ increases the MRR linearly; however, an increase in the value of $d_{i}$ decreases the MRR marginally. As observed, the MRR increases with the rise in $f_{z}$ value. While machining with a higher $f_{z}$ value $(0.06 \mathrm{~mm} / \mathrm{z})$, the distance traversed by the tool per unit time is higher than that at a low feed condition $(0.02 \mathrm{~mm} / \mathrm{z})$, thus increasing the volume of material removal. Theoretically, the MRR increases with an increase in $d_{i}$. But in the present experimental study, it is noted that MRR decreases with the rise in $d_{i}$. The MRR is computed based on the time duration that a tool takes to machine the thin-wall part per the desired dimension completely. But in practice, during $\mathrm{CNC}$ milling, it is essential to provide sufficient ramp-on (tool approach to work part) and ramp-off (tool disengagement from work part) clearance. Ramp-on and ramp-off distances are directly proportional to the tool diameter. Thus, with the higher diameter tool, the tool travel time increases, eventually reducing the MRR. Further, an increase in MRR with $a_{d}$ is ascribed to the fact that the material removed mainly depends on the work-tool contact. As contact length increases, the amount of material machined increases, thus enhancing productivity. Similarly, the MRR increases with an increase in $r_{d}$. As $r_{d}$ increases, the amount of cutter immersion increases, which further improves the material removal. Thus, it can be concluded that the rate of material removal can be maximized using a high depth of cut and feed values. Figure $9 b-d$ shows the 3D response plots indicating the interactive effect between the process parameters for MRR. The response plots show an increasing MRR trend with the increase in $d_{i}, f_{z}$, $a_{d}$, and $r_{d}$.

The ANOVA indicates that $f_{z}, a_{d}$, and $r_{d}$ with contributions of $19.57 \%, 22.05 \%$, and $37.56 \%$ significantly influence the MRR. Consequently, the MRR can be maximized by increasing the $f_{z}, a_{d}$, and $r_{d}$ values. However, it is to be noted that MRR also influences the product quality during the thin-wall machining process. Reported research suggests a practical limit on $n_{s}$ and $f_{z}$ at which milling machines can be operated without deteriorating the

$$
\mathrm{MRR}=\left[\begin{array}{l}
3989.17-72.60 \cdot d_{i}-72758.49 \cdot f_{z}-197.28 \cdot a_{d}-5944.23 \cdot r_{d} \\
+5032 \cdot f_{z} \cdot a_{d}+1.039 e^{+5} \cdot f_{z} \cdot r_{d}+317.55 \cdot a_{d} \cdot r_{d}+1271.41 \cdot r_{d}^{2}
\end{array}\right]
$$




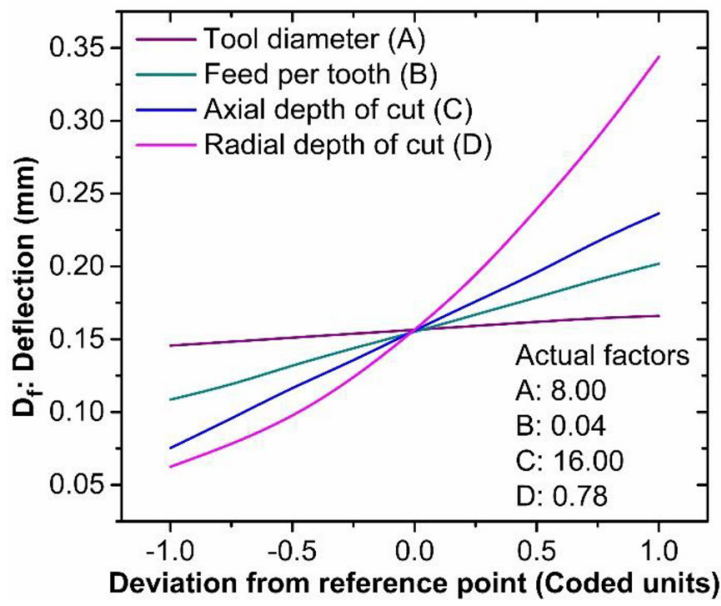

(a)
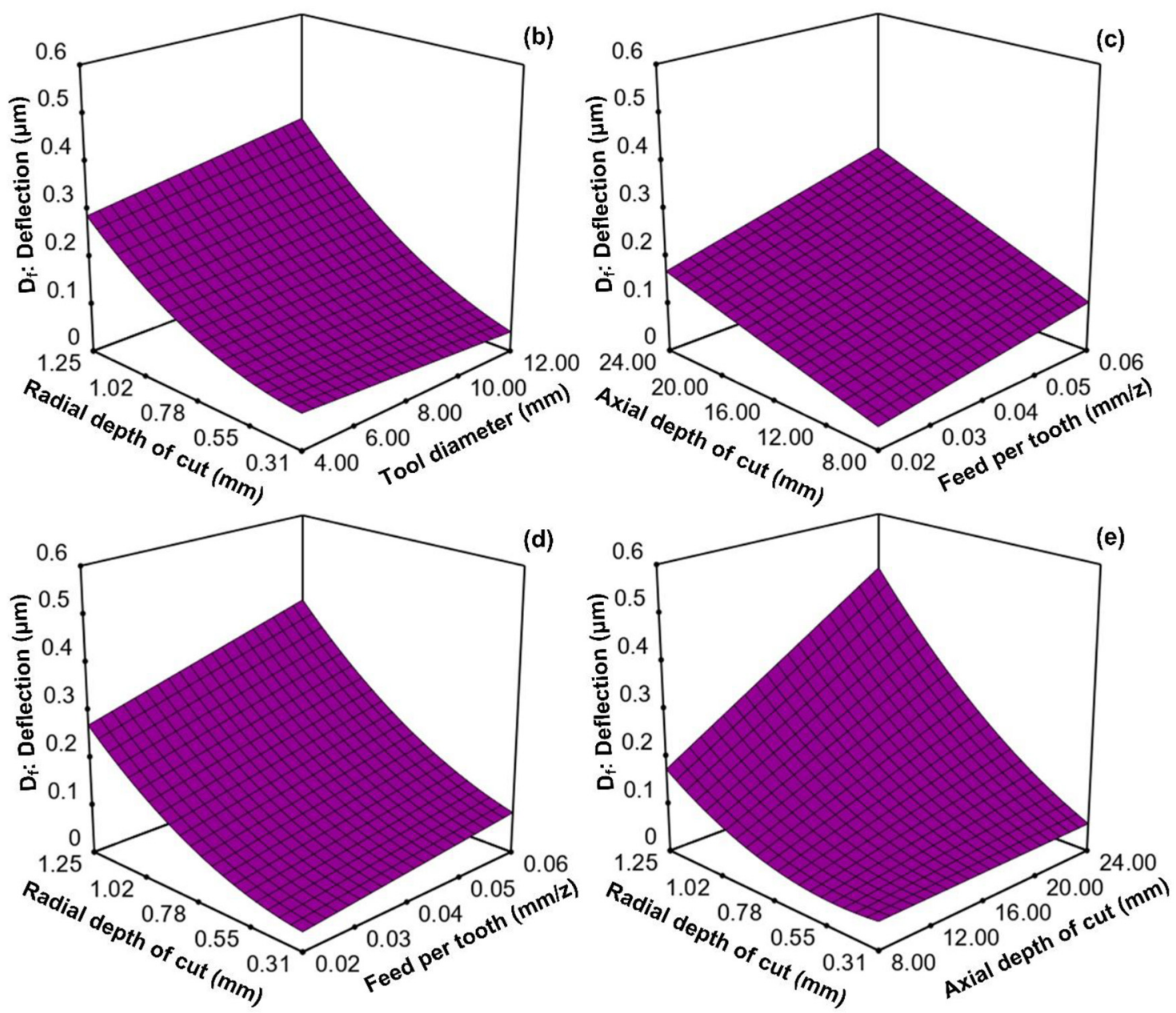

Fig. 5. Analysis of wall deflection (a) Perturbation plot; (b) Interaction of $d_{i}$ and $r_{d}$; (c) Interaction of $f_{z}$ and $a_{d}$, (d) Interaction of $f_{z}$ and $r_{d} ;$ (e) Interaction of $a_{d}$ and $r_{d}$.

part quality $[23,25]$. But limited inquiries have been made on the practical limits of $a_{d}$ and $r_{d}$ on MRR. Therefore, MRR as a function of $a_{d}$ and $r_{d}$ and their influence on product quality is further investigated. From Figure $5 \mathrm{a}$, it can be noted that wall deflection increases with $a_{d}$. Increment in $a_{d}$ and $r_{d}$ from level 1 to level 2 has a minimal influence on wall deflection, but further increase in $a_{d}$ to $24 \mathrm{~mm}$ and $r_{d}$ to $1.25 \mathrm{~mm}$ drastically increases the magnitude of wall deflection. Therefore, the efforts to improve the MRR by using higher values of $a_{d}$ and $r_{d}$ leads to excessive wall deflection, negatively affecting the dimensional accuracy as seen in Figures 6 and 7, respectively. Also, the increase in MRR affects the surface finish.

Figures 10a and 10b shows the machined surface topography indicating the presence of chatter marks while machining with an $a_{d}$ value of $24 \mathrm{~mm}$ and $r_{d}$ value of 


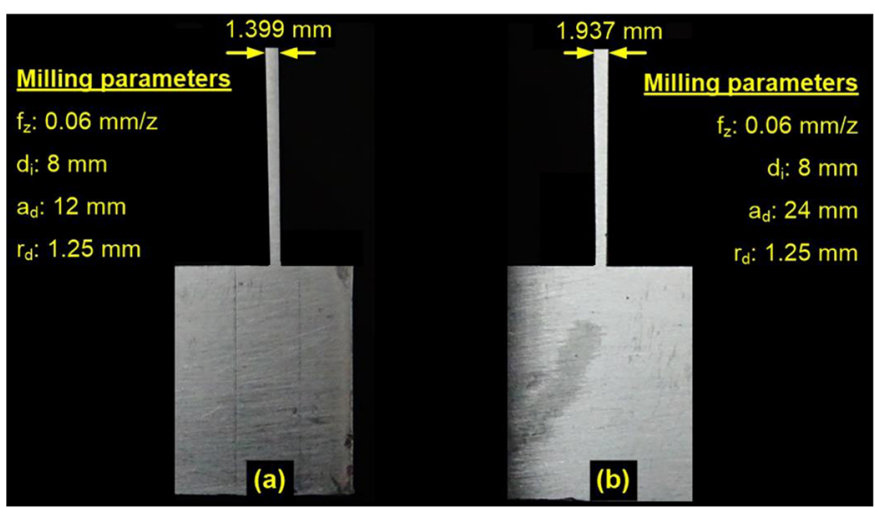

Fig. 6. Side profile of a thin-wall machined with $a_{d}$ of (a) $12 \mathrm{~mm}$; (b) 24 .

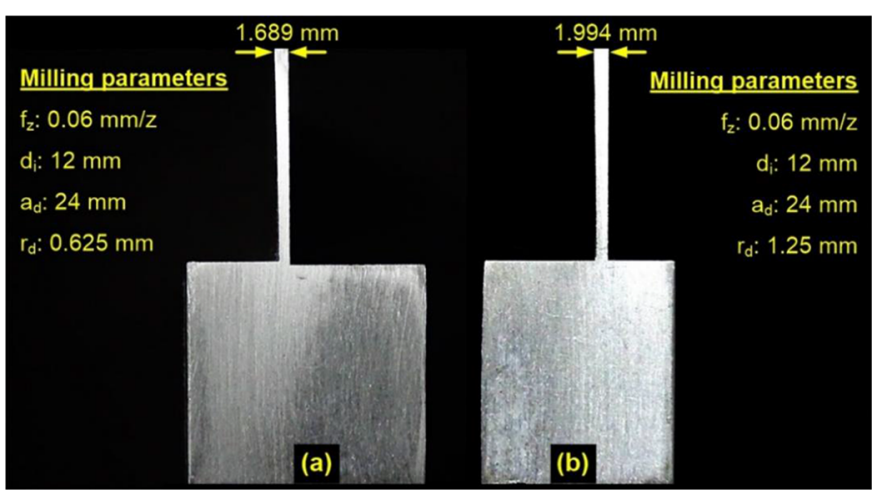

Fig. 7. Side profile of a thin-wall machined with $r_{d}$ of (a) $0.625 \mathrm{~mm}$; (b) $1.25 \mathrm{~mm}$.

Table 3. ANOVA for the quadratic model of MRR (after elimination).

\begin{tabular}{llllll}
\hline Source & Sum of squares & DF & Mean square & $F$-value & $p$-value \\
\hline Model & $5.841 \mathrm{E}+08$ & 8 & $7.301 \mathrm{E}+07$ & 531.85 & $<0.0001$ \\
$d_{i}$ & $4.215 \mathrm{E}+06$ & 1 & $4.215 \mathrm{E}+06$ & 30.70 & $<0.0001$ \\
$f_{z}$ & $1.497 \mathrm{E}+08$ & 1 & $1.497 \mathrm{E}+08$ & 1090.72 & $<0.0001$ \\
$a_{d}$ & $2.146 \mathrm{E}+08$ & 1 & $2.146 \mathrm{E}+08$ & 1562.99 & $<0.0001$ \\
$r_{d}$ & $2.873 \mathrm{E}+08$ & 1 & $2.873 \mathrm{E}+08$ & 2092.69 & $<0.0001$ \\
$f_{z^{*}} a_{d}$ & $2.416 \mathrm{E}+07$ & 1 & $2.416 \mathrm{E}+07$ & 176.03 & $<0.0001$ \\
$f_{z^{*}} r_{d}$ & $3.250 \mathrm{E}+07$ & 1 & $3.250 \mathrm{E}+07$ & 236.73 & $<0.0001$ \\
$a_{d} * r_{d}$ & $5.134 \mathrm{E}+07$ & 1 & $5.134 \mathrm{E}+07$ & 374.00 & $<0.0001$ \\
$r_{d}^{2}$ & $1.058 \mathrm{E}+06$ & 1 & $1.058 \mathrm{E}+06$ & 7.71 & 0.0071 \\
Residual & $9.472 \mathrm{E}+06$ & 69 & $1.373 \mathrm{E}+05$ & & \\
Cor. Total & $5.935 \mathrm{E}+08$ & 77 & & & \\
\hline
\end{tabular}
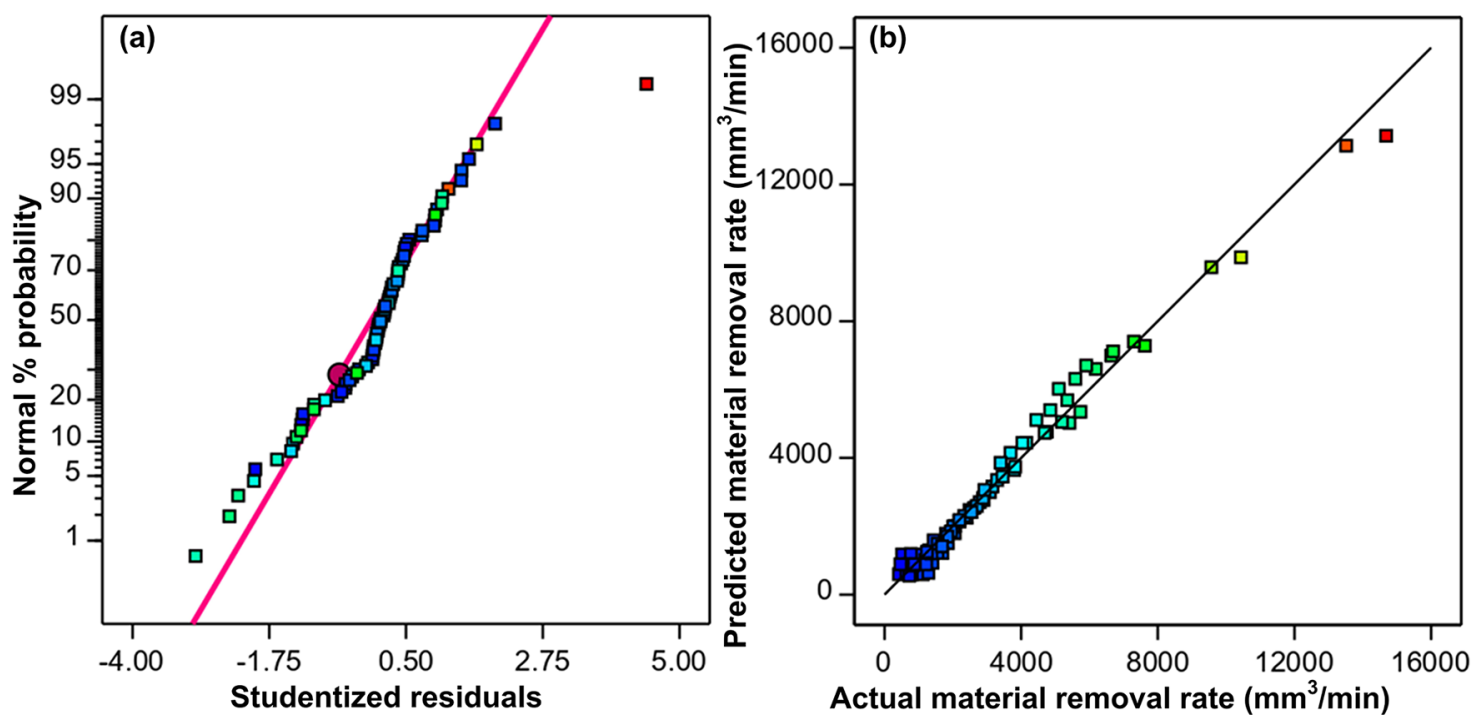

Fig. 8. (a) Normal probability plot of studentized residuals; (b) Plot of actual vs. predicted response for MRR. 

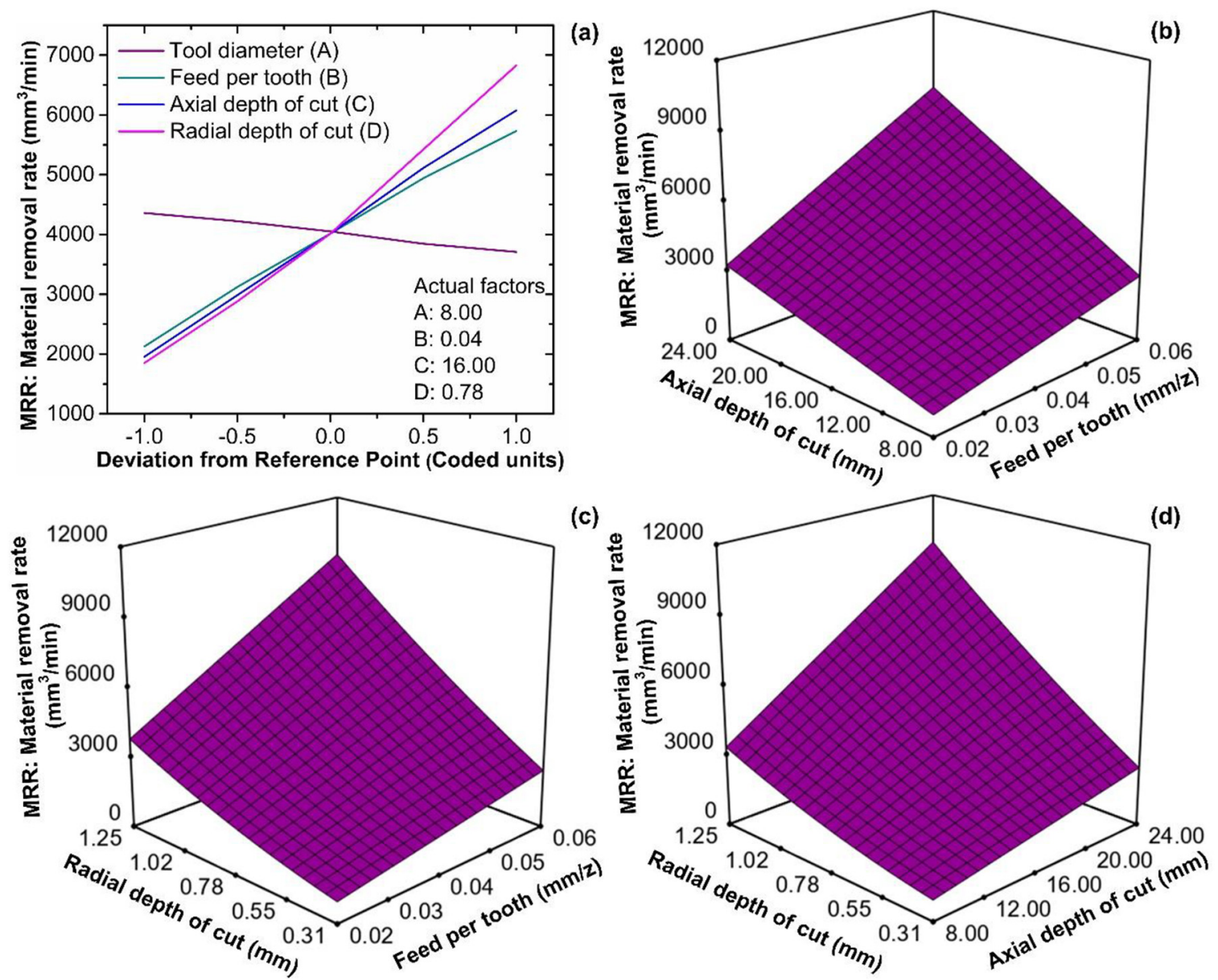

Fig. 9. Analysis of MRR (a) Perturbation plot; (b) Interaction of $f_{z}$ and $a_{d}$; (c) Interaction of $f_{z}$ and $r_{d}$; (d) Interaction of $a_{d}$ and $r_{d}$.

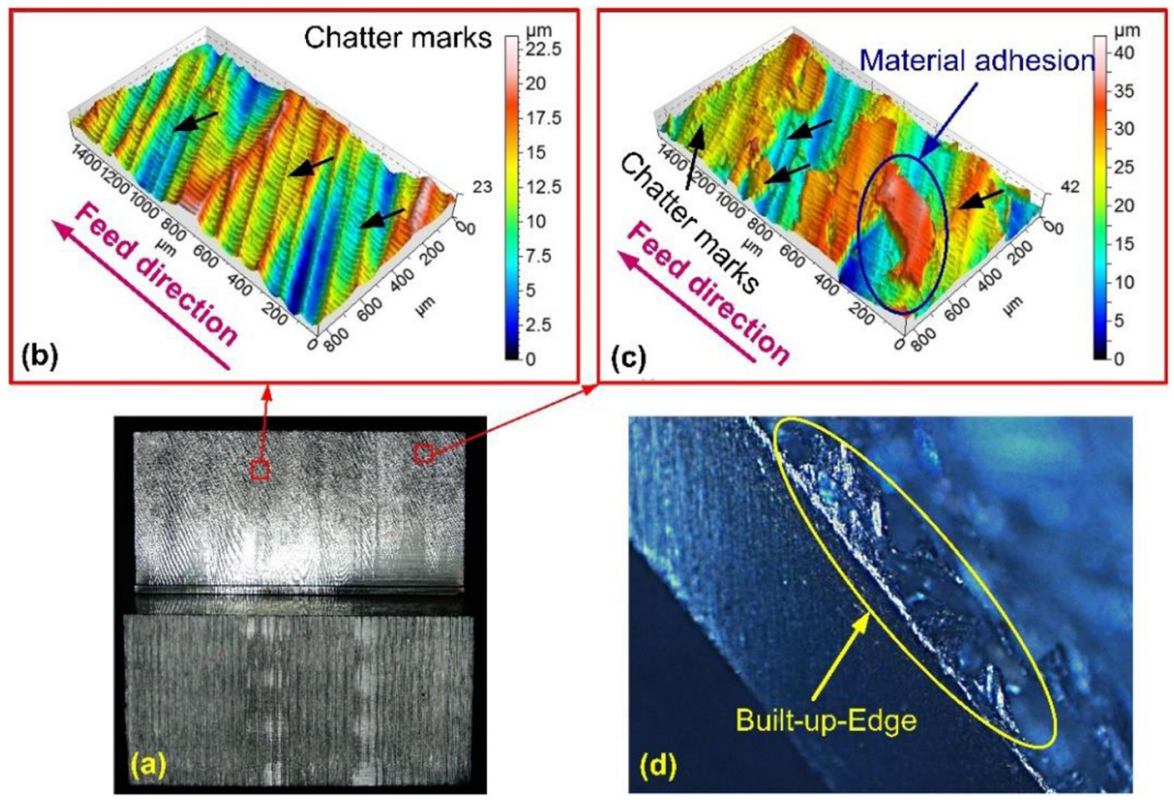

Fig. 10. (a) Chatter marks on workpiece machined at $a_{d}$ of $24 \mathrm{~mm}$ and $r_{d}$ of $1.25 \mathrm{~mm}$ using 4 mm diameter tool; (b) surface profile indicating chatter; (c) material adhesion on the work surface; (d) built-up-edge formed at the cutting edge. 
$1.25 \mathrm{~mm}$. Also, machining under such process conditions of $a_{d}$ and $r_{d}$ using a $4 \mathrm{~mm}$ diameter end mill results in material adhesion (see Fig. 10c) and built-up-edge formation at the tool cutting edge (see Fig. 10d). The observations verify that increasing the $f_{z}, a_{d}$, and $r_{d}$ increases productivity at the expense of surface quality. Therefore, it is crucial to select optimal process conditions that can prevent chatter and simultaneously improve MRR.

\subsection{Optimization using NSGA-II}

Thin-wall machining is an intense process, where 90-95\% of the material is machined to produce the final components [1]. Therefore, it is essential to maximize the MRR while simultaneously maintaining the dimensional accuracy by minimizing the wall deflection. To handle such a conflicting multi-objective optimization problem, NSGA-II is utilized. The objective functions for the present study are given by,

$$
\left.\begin{array}{l}
\text { Objective } 1: \text { Minimize }\left[D_{f}\right] \\
\text { Objective } 2: \text { Maximize }[\mathrm{MRR}]
\end{array}\right\}
$$

The empirical mathematical equations (1) and (2) for wall deflection and MRR obtained using the regression method are used as the objective functions for optimizing

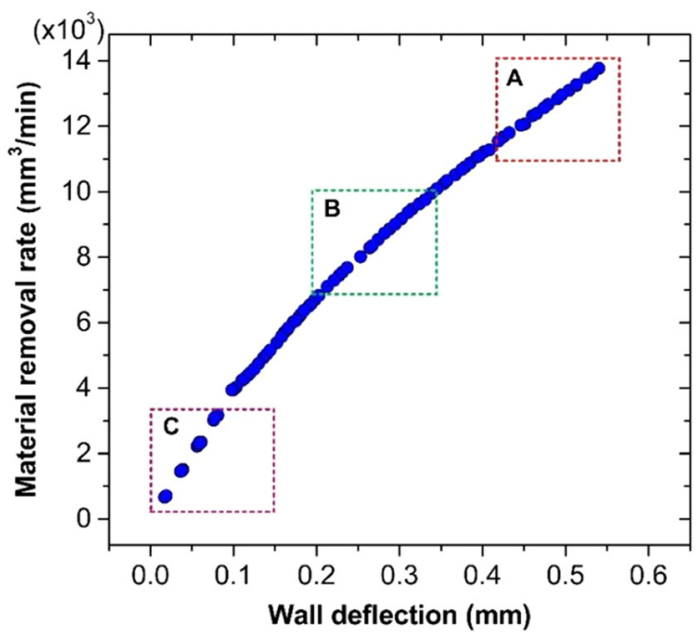

Fig. 11. Pareto fronts between wall deflection and MRR produced by NSGA-II. using NSGA-II.

$$
\left.\begin{array}{l}
\text { Tool diameter }\left(d_{i}\right): 4 \text { to } 12 \mathrm{~mm} \\
\text { Feed per tooth }\left(f_{z}\right): 0.02 \text { to } 0.06 \mathrm{~mm} / \mathrm{z} \\
\text { Axial depth of cut }\left(a_{d}\right): 8 \text { to } 24 \mathrm{~mm} \\
\text { Radial depth of cut }\left(r_{d}\right): 0.3125 \text { to } 1.25 \mathrm{~mm}
\end{array}\right\}
$$

In the optimization procedure, a population size of 100 is considered, and binary tournament selection is adapted. The uniform crossover operator is applied with a probability of 0.8 , and mutation is set as constraint dependent. Figure 11 shows the Pareto-optimal front between wall deflection and MRR obtained by NSGA-II after optimization. The optimum solutions predicted using NSGA-II have no predominance over another. All the points in the Pareto-optimal front denote a combination of machining parameters. Any of the solution sets can be used based on the desired response criteria.

The cost of production can be reduced by reducing production time. This can be achieved by improving the MRR. As seen from Figure 11, the Pareto-optimal solutions in region 'A' help increase the MRR. Some Pareto-optimal solutions for obtaining high MRR are listed in Table 4. Experiments are carried out using a $5 \mathrm{~mm}$ diameter end mill considering solution set 4 listed in Table 4 . The use of recommended process parameters results in an MRR value of $15740.7 \mathrm{~mm}^{3} / \mathrm{min}$. But the magnitude of wall deflection is significantly larger, thus resulting in poor dimensional accuracy (see Fig. 12a). If surface quality is considered, the recommended optimal solution results in poor surface finish due to chatter, as seen in Figure 12b. Therefore, if the objective is to increase the MRR without taking into consideration the surface finish and form error, which is usually the case when machining the bulk of the material, Pareto-optimal solutions in region ' $\mathrm{A}$ ' can be considered.

When a balance between the MRR and wall deflection is desirable, solutions indicated in region ' $\mathrm{B}$ ' can be used. Table 5 lists some of the Pareto-optimal solutions in region ' $\mathrm{B}$ '. Experiments are carried out using a $5 \mathrm{~mm}$ diameter end mill considering solution set 2 listed in Table 5 . The use of recommended process parameters resulted in an MRR value of $7169.63 \mathrm{~mm}^{3} / \mathrm{min}$. Additionally, as seen from Figure 13a, in-process wall deflection results in form error and mild chatter, which deteriorates the surface finish (see Fig. 13b).

Table 4. Some optimum combinations of parameters based on Pareto front in region 'A'.

\begin{tabular}{lllllll}
\hline Sol. set & $d_{i}(\mathrm{~mm})$ & $f_{z}(\mathrm{~mm} / \mathrm{z})$ & $a_{d}(\mathrm{~mm})$ & $r_{d}(\mathrm{~mm})$ & $D_{f}(\mathrm{~mm})$ & $\mathrm{MRR}\left(\mathrm{mm}^{3} / \mathrm{min}^{2}\right.$ \\
\hline 1 & 4.9 & 0.06 & 23.84 & 1.1162 & 0.540 & 13768.82 \\
2 & 4.9 & 0.06 & 23.87 & 0.9416 & 0.465 & 12389.27 \\
3 & 4.9 & 0.06 & 23.83 & 1.1938 & 0.367 & 10514.42 \\
4 & 4.9 & 0.06 & 23.86 & 1.2230 & 0.513 & 13249.08 \\
5 & 4.9 & 0.06 & 23.83 & 1.1572 & 0.490 & 12839.32 \\
\hline
\end{tabular}



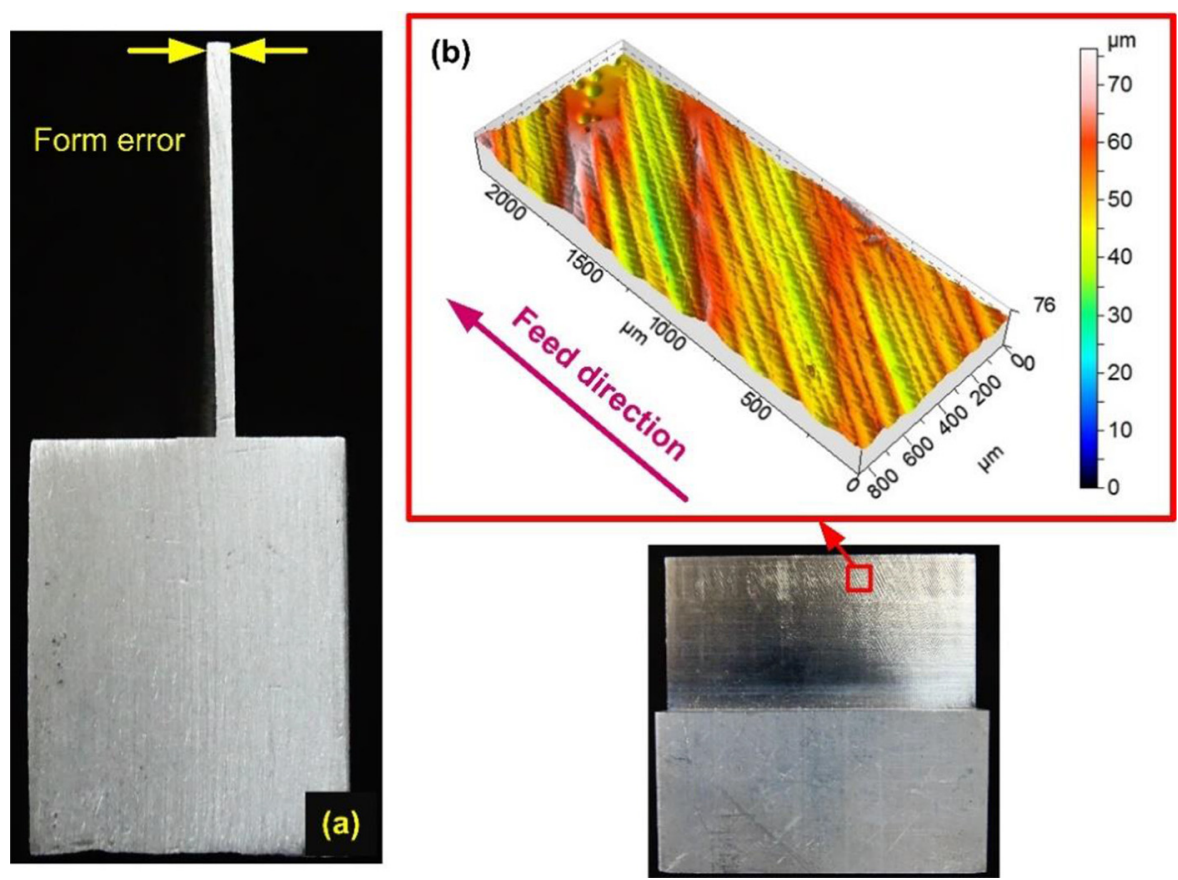

Fig. 12. (a) Form error; (b) Surface profile and topograph obtained for the optimal solution set 4 in the region 'A'.

Table 5. Some optimum combinations of parameters based on Pareto front in region 'B'.

\begin{tabular}{lllllll}
\hline Sol. set & $d_{i}(\mathrm{~mm})$ & $f_{z}(\mathrm{~mm} / \mathrm{z})$ & $a_{d}(\mathrm{~mm})$ & $r_{d}(\mathrm{~mm})$ & $D_{f}(\mathrm{~mm})$ & $\mathrm{MRR}\left(\mathrm{mm}^{3} / \mathrm{min}^{2}\right.$ \\
\hline 1 & 5.2 & 0.06 & 23.82 & 0.7030 & 0.253 & 8014.96 \\
2 & 4.9 & 0.06 & 23.83 & 0.7714 & 0.282 & 8736.28 \\
3 & 4.9 & 0.06 & 23.83 & 0.8138 & 0.302 & 9167.89 \\
4 & 4.8 & 0.06 & 23.83 & 0.5295 & 0.185 & 6374.60 \\
5 & 4.9 & 0.06 & 23.81 & 0.7992 & 0.295 & 9011.29 \\
\hline
\end{tabular}
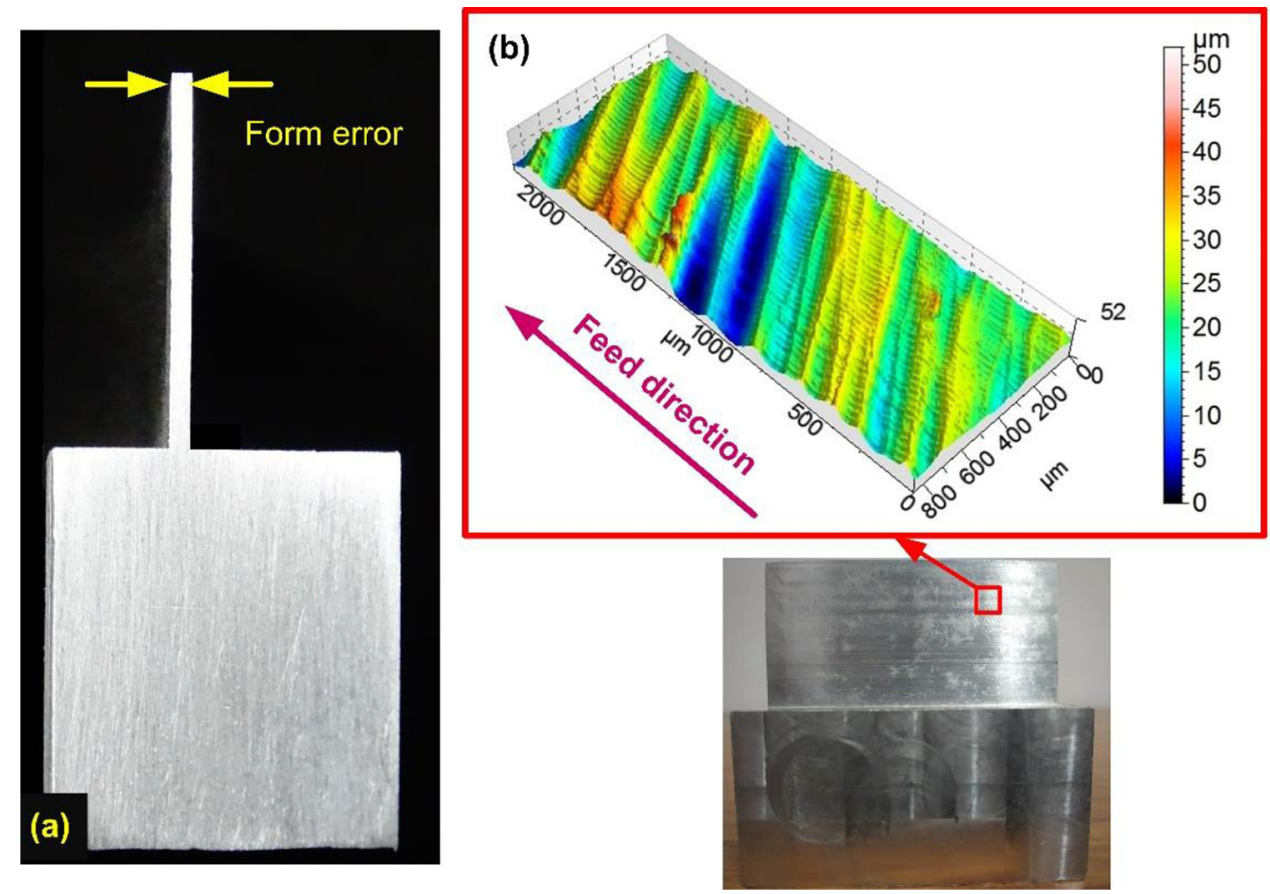

Fig. 13. (a) Form error; (b) Surface profile and topograph obtained for the optimal solution set 2 in region 'B'. 
Table 6. Optimum combinations of parameters based on Pareto front.

\begin{tabular}{lllllll}
\hline Sol. set & $d_{i}(\mathrm{~mm})$ & $f_{z}(\mathrm{~mm} / \mathrm{z})$ & $a_{d}(\mathrm{~mm})$ & $r_{d}(\mathrm{~mm})$ & $D_{f}(\mathrm{~mm})$ & $\mathrm{MRR}\left(\mathrm{mm}^{3} / \mathrm{min}^{2}\right.$ \\
\hline 1 & 11 & 0.05 & 23.07 & 0.3203 & 0.076 & 3017.31 \\
2 & 10.8 & 0.06 & 23.57 & 0.3244 & 0.099 & 3936.21 \\
3 & 6.2 & 0.06 & 23.7 & 0.3521 & 0.125 & 4586.05 \\
4 & 10.5 & 0.05 & 23.51 & 0.3270 & 0.081 & 3172.11 \\
5 & 9.9 & 0.06 & 23.52 & 0.3269 & 0.103 & 4021.17 \\
\hline
\end{tabular}

Table 7. Confirmation experiments for finish machining of thin-walls.

\begin{tabular}{|c|c|c|c|c|}
\hline \multicolumn{3}{|l|}{ Sol. set } & \multirow{2}{*}{$\begin{array}{l}4 \\
10\end{array}$} & \multirow{2}{*}{$\begin{array}{l}5 \\
10\end{array}$} \\
\hline \multirow{5}{*}{ Milling parameters } & & $d_{i}(\mathrm{~mm})$ & & \\
\hline & & $f_{z}(\mathrm{~mm} / \mathrm{z})$ & 0.05 & 0.06 \\
\hline & & $a_{d}(\mathrm{~mm})$ & 24 & 24 \\
\hline & & $r_{d}(\mathrm{~mm})$ & 0.33 & 0.33 \\
\hline & & Experiment & 0.103 & 0.112 \\
\hline \multirow{5}{*}{ Responses } & $D_{f}(\mathrm{~mm})$ & Predicted & 0.081 & 0.103 \\
\hline & & Absolute error (\%) & 21.36 & 8.03 \\
\hline & & Experiment & 3469.38 & 3634.21 \\
\hline & $\operatorname{MRR}\left(\mathrm{mm}^{3} / \mathrm{min}\right)$ & Predicted & 3172.11 & 4021.17 \\
\hline & & Absolute error (\%) & 8.56 & 9.62 \\
\hline
\end{tabular}

The production of highly accurate components is a crucial requirement in modern aerospace industries. In thin-wall machining, surface quality in terms of surface roughness is directly related to the quality of products because it influences the part functionality [26]. Therefore, the determination of optimal process parameters becomes essential. Based on the analysis, Pareto solutions situated in region ' $\mathrm{C}$ ' can be used to finish machine the thin-wall parts. Some of the Pareto-optimal solutions are listed in Table 6. Experiments are carried out considering solution sets 4 and 5 listed in Table 6 . Confirmation experiments are performed to verify the prediction using a standard $10 \mathrm{~mm}$ diameter end mill. The measured MRR and deflection values are listed in Table 7 . The deflection magnitude is lower, with the predicted wall deflection being closer to the experimentally measured values. There is a reduction in form error, as seen in Figure 14a. Furthermore, the absolute average error of productivity (MRR) is no more than $10 \%$ for the recommended process conditions. Also, a better quality surface is obtained, as seen from Figure 14b. The result indicates the Pareto-optimal solutions in region ' $\mathrm{C}$ ' can be regarded as guidelines for finish machining thinwall parts with improved dimensional accuracy and surface finish.

\section{Conclusions}

The study investigated the influence of feed per tooth, axial depth of cut, radial depth of cut, and tool diameter on wall deflection (product quality) and MRR (productivity) during the thin-wall machining process. The process was systematically analyzed using ANOVA, and multi-objective optimization was carried using NSGA-II. The summarized results are as follows:

- A substantial rise in the in-process wall deflection was noted at the higher feed, axial depth, and radial depth of cut values due to the generation of larger cutting forces. The ANOVA indicated that $a_{d}$ and $r_{d}$ significantly influenced the wall deflection with contributions of $20.31 \%$ and $55.82 \%$, respectively. Also, the magnitude of in-process deflection was larger when thin-walls were machined with a larger diameter end mill.

- MRR increased with an increase in feed, axial, and radial depth of cut values. The ANOVA indicated that $f_{z}, a_{d}$, and $r_{d}$ with contributions of $19.57 \%, 22.05 \%$, and $37.56 \%$ significantly influenced the MRR. However, the material removal rate lowered when end mills with larger diameters were used to mill the thin-wall parts.

- Maximization of MRR deteriorated the surface finish of the machined thin-wall parts. Employment of high axial and radial depth of cut conditions caused the low rigidity wall to defect, thus increasing the severity of the chatter.

- Due to the complex and adverse nature of wall deflection and MRR, multi-objective optimization was carried out to optimize the process performance. The predicted Pareto solutions could identify the suitable combinations of process variables to increase the MRR. Furthermore, the model could predict the optimal combination of process variables needed to lower the in-process wall deflection and maintain a superior surface finish. 

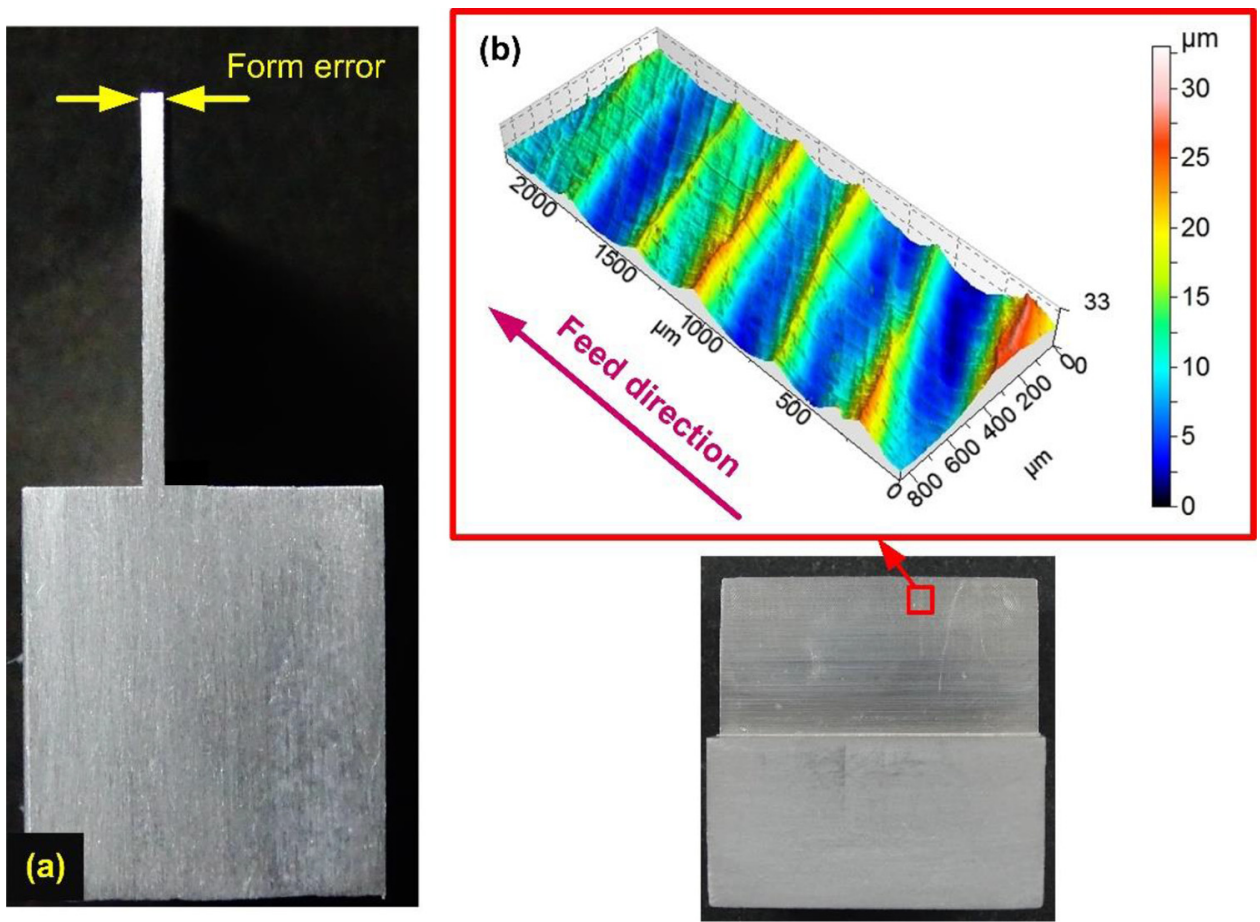

Fig. 14. (a) Form error; (b) Surface profile and topograph obtained for an optimal solution in region 'C' (Sol. No. 4 in Tab. 6 ).

Acknowledgements. This work was supported by the Science and Engineering Research Board (SERB), Department of Science and Technology, Government of India (Grant number: SR-S3-MERC-0115-2012).

\section{References}

1. G. Bolar, S.N. Joshi, Int. J. Mater. Form Mach. Proc. 5 (2018) 13

2. S. Seguy, F.J. Campa, L.N. Lopez de Lacalle, L. Arnaud, G. Dessein, G. Aramendi, Int. J. Mach. Mach. Mater. 4 (2008) 377

3. M. Luo, D. Liu, H. Luo, Sensors 16 (2016) 1470

4. H. Ning, W. Zhigang, J. Chengyu, Z. Bing, J. Mater. Process Technol. 139 (2003) 332

5. S.G. Wang, Y.L. Hsu, Proc. Inst. Mech. Eng. B J. Eng. Manuf. 219 (2005) 177

6. S. Herranz, F.J. Campa, L.N. Lopez de Lacalle, A. Rivero, A. Lamikiz, E. Ukar, J.A. Sánchez, U. Bravo, Proc. Inst. Mech. Eng. B. J. Eng. Manuf. 219 (2005) 789

7. V.S. Rao, P.V.M. Rao, Proc. Inst. Mech. Eng. B. J. Eng. Manuf. 220 (2006) 1399

8. X.J. Zhang, C.H. Xiong, Y. Ding, X.M. Zhang, Proc. Inst. Mech. Eng. B. J. Eng. Manuf. 224 (2010) 589

9. B. Han, C.Z. Ren, X.Y. Yang, G. Chen, Mater. Sci. Forum 697 (2012) 129
10. S.A. Abbasi, P.F. Feng, Y. Ma, X.C. Cai, D.W. Yu, Z.J. Wu, Key Eng. Mater. 693 (2016) 1038

11. S.N. Joshi, G. Bolar, J. Inst. Eng. (India) Ser. C 98 (2017) 343

12. G. Bolar, S.N. Joshi, Proc. Inst. Mech. Eng. B. J. Eng. Manuf. 231 (2017) 792

13. G. Bolar, A. Das, S.N. Joshi, Measurement 121 (2018) 190

14. S. Wang, Z. Jia, X. Lu, H. Zhang, C. Zhang, S.Y. Liang, Simulation 94 (2018) 67

15. Z. Du, D. Zhang, H. Hou, S.Y. Liang, Int. J. Adv. Manuf. Technol. 88 (2017) 3405

16. Z.L. Li, L.M. Zhu, Precis. Eng. 55 (2019) 77

17. I. Del Sol, A. Rivero, A.J. Gamez, Metals 9 (2019) 927

18. S. Qu, J. Zhao, T. Wang, Int. J. Adv. Manuf. Technol. 89 (2017) 2399

19. J. Vukman, D. Lukic, S. Borojevic, D. Rodic, M. Milosevic, Int. J. Precis. Eng. Manuf. 21 (2020) 91

20. G. Bolar, S.N. Joshi, Int. J. Mach. Mach. Mater. 22 (2020) 212

21. K. Ringgaard, Y. Mohammadi, C. Merrild, O. Balling, K. Ahmadi, Int. J. Mach. Tool. Manuf. 145 (2019) 103430

22. D.J. Cheng, F. Xu, S.H. Xu, C.Y. Zhang, S.W. Zhang, S.J. Kim, Int. J. Mach. Tool. Manuf. 21 (2020) 1597

23. E. Budak, Int. J. Mach. Tool. Manuf. 46 (2006) 1478

24. V. Thévenot, L. Arnaud, G. Dessein, G. Cazenave-Larroche, Mach. Sci. Technol. 10 (2006) 275

25. A. Tang, Z. Liu, Int. J. Adv. Manuf. Technol. 43 (2009) 33

26. A. Javidi, U. Rieger, W. Eichlseder, Int. J. Fatigue 30 (2008) 2050

Cite this article as: Gururaj Bolar, Shrikrishna Nandkishor Joshi, Experimental investigation and optimization of wall deflection and material removal rate in milling thin-wall parts, Manufacturing Rev. 8, 17 (2021) 


\section{Appendix A}

Table A1. $3^{4}$ full factorial machining experiment results.

\begin{tabular}{|c|c|c|c|c|c|c|}
\hline \multirow[t]{2}{*}{ Run no. } & \multicolumn{4}{|c|}{ Milling parameters } & \multicolumn{2}{|c|}{ Response parameters } \\
\hline & $d_{i}(\mathrm{~mm})$ & $f_{z}(\mathrm{~mm} / \mathrm{z})$ & $a_{d}(\mathrm{~mm})$ & $r_{d}(\mathrm{~mm})$ & $D_{f}(\mathrm{~mm})$ & $\operatorname{MRR}\left(\mathrm{mm}^{3} / \mathrm{min}\right)$ \\
\hline 1 & 12 & 0.06 & 8 & 0.3125 & 0.077 & 1119.4 \\
\hline 2 & 12 & 0.02 & 8 & 0.3125 & 0.021 & 426.231 \\
\hline 3 & 12 & 0.04 & 12 & 0.625 & 0.077 & 2063.11 \\
\hline 4 & 12 & 0.02 & 12 & 0.625 & 0.054 & 1093.8 \\
\hline 5 & 8 & 0.06 & 24 & 0.3125 & 0.093 & 3692.09 \\
\hline 6 & 8 & 0.06 & 8 & 1.25 & 0.222 & 4854.06 \\
\hline 7 & 8 & 0.02 & 8 & 1.25 & 0.178 & 1855.67 \\
\hline 8 & 4 & 0.06 & 8 & 0.3125 & 0.068 & 1340.69 \\
\hline 9 & 4 & 0.02 & 8 & 1.25 & 0.098 & 2057.01 \\
\hline 10 & 8 & 0.02 & 12 & 1.25 & 0.227 & 2785.87 \\
\hline 11 & 12 & 0.04 & 8 & 0.3125 & 0.059 & 795.88 \\
\hline 12 & 12 & 0.06 & 24 & 0.3125 & 0.141 & 3396.98 \\
\hline 13 & 12 & 0.02 & 8 & 1.25 & 0.189 & 1693.04 \\
\hline 14 & 12 & 0.04 & 12 & 1.25 & 0.276 & 4753.03 \\
\hline 15 & 12 & 0.04 & 24 & 0.625 & 0.124 & 4148.59 \\
\hline 16 & 8 & 0.02 & 24 & 1.25 & 0.394 & 5585.98 \\
\hline 17 & 4 & 0.04 & 24 & 1.25 & $*$ & $*$ \\
\hline 18 & 12 & 0.02 & 24 & 1.25 & 0.411 & 5101.7 \\
\hline 19 & 12 & 0.02 & 12 & 0.3125 & 0.026 & 640.06 \\
\hline 20 & 8 & 0.04 & 24 & 0.625 & 0.095 & 4690.37 \\
\hline 21 & 4 & 0.06 & 8 & 0.625 & 0.112 & 2528.09 \\
\hline 22 & 4 & 0.02 & 24 & 1.25 & 0.329 & 6181.82 \\
\hline 23 & 8 & 0.04 & 24 & 0.3125 & 0.077 & 2623.46 \\
\hline 24 & 4 & 0.06 & 24 & 0.3125 & 0.114 & 4039.07 \\
\hline 25 & 4 & 0.06 & 12 & 0.3125 & 0.081 & 2013.16 \\
\hline 26 & 4 & 0.02 & 8 & 0.625 & 0.069 & 964.691 \\
\hline 27 & 4 & 0.02 & 12 & 1.25 & 0.139 & 3086.54 \\
\hline 28 & 12 & 0.06 & 8 & 1.25 & 0.232 & 4447.67 \\
\hline 29 & 4 & 0.04 & 8 & 0.3125 & 0.052 & 957.447 \\
\hline 30 & 8 & 0.04 & 12 & 0.3125 & 0.047 & 1305.91 \\
\hline 31 & 4 & 0.02 & 8 & 0.3125 & 0.026 & 515.429 \\
\hline 32 & 8 & 0.02 & 24 & 0.625 & 0.075 & 2492.67 \\
\hline 33 & 12 & 0.04 & 12 & 0.3125 & 0.072 & 1196.06 \\
\hline 34 & 4 & 0.04 & 8 & 0.625 & 0.091 & 1799.15 \\
\hline 35 & 8 & 0.06 & 8 & 0.625 & 0.08 & 2194.49 \\
\hline 36 & 12 & 0.06 & 8 & 0.625 & 0.089 & 1946.57 \\
\hline 37 & 12 & 0.06 & 24 & 0.625 & 0.168 & 5902.78 \\
\hline 38 & 12 & 0.02 & 24 & 0.3125 & 0.071 & 1284.42 \\
\hline 39 & 4 & 0.02 & 12 & 0.3125 & 0.056 & 773.509 \\
\hline 40 & 4 & 0.06 & 12 & 0.625 & 0.221 & 3796.53 \\
\hline 41 & 4 & 0.02 & 24 & 0.625 & 0.138 & 2898.83 \\
\hline 42 & 4 & 0.04 & 12 & 0.625 & 0.171 & 2701.27 \\
\hline 43 & 4 & 0.04 & 24 & 0.3125 & 0.081 & 2882.44 \\
\hline 44 & 12 & 0.06 & 24 & 1.25 & 0.67 & 13515.9 \\
\hline 45 & 12 & 0.02 & 8 & 0.625 & 0.041 & 728.571 \\
\hline
\end{tabular}


Table A1. (continued).

\begin{tabular}{|c|c|c|c|c|c|c|}
\hline \multirow[t]{2}{*}{ Run no. } & \multicolumn{4}{|c|}{ Milling parameters } & \multicolumn{2}{|c|}{ Response parameters } \\
\hline & $d_{i}(\mathrm{~mm})$ & $f_{z}(\mathrm{~mm} / \mathrm{z})$ & $a_{d}(\mathrm{~mm})$ & $r_{d}(\mathrm{~mm})$ & $D_{f}(\mathrm{~mm})$ & $\operatorname{MRR}\left(\mathrm{mm}^{3} / \mathrm{min}\right)$ \\
\hline 46 & 8 & 0.02 & 12 & 0.3125 & 0.021 & 700.678 \\
\hline 47 & 8 & 0.06 & 24 & 1.25 & 0.615 & 14683.3 \\
\hline 48 & 8 & 0.02 & 8 & 0.625 & 0.0316 & 828.281 \\
\hline 49 & 12 & 0.04 & 8 & 1.25 & 0.228 & 3161.81 \\
\hline 50 & 4 & 0.04 & 8 & 1.25 & 0.138 & 3821.18 \\
\hline 51 & 8 & 0.02 & 24 & 0.3125 & 0.046 & 1404.7 \\
\hline 52 & 8 & 0.06 & 12 & 0.3125 & 0.065 & 1834.53 \\
\hline 53 & 12 & 0.04 & 24 & 0.3125 & 0.097 & 2407.17 \\
\hline 54 & 4 & 0.02 & 12 & 0.625 & 0.136 & 1447.77 \\
\hline 55 & 8 & 0.04 & 24 & 1.25 & 0.547 & 10436.6 \\
\hline 56 & 4 & 0.02 & 24 & 0.3125 & 0.0588 & 1549.21 \\
\hline 57 & 8 & 0.04 & 12 & 0.625 & 0.07 & 2334.45 \\
\hline 58 & 4 & 0.06 & 24 & 0.625 & 0.226 & 7619.52 \\
\hline 59 & 8 & 0.02 & 8 & 0.3125 & 0.013 & 466.691 \\
\hline 60 & 4 & 0.04 & 24 & 0.625 & 0.174 & 5414.01 \\
\hline 61 & 4 & 0.06 & 8 & 1.25 & 0.186 & 5351.52 \\
\hline 62 & 8 & 0.06 & 24 & 0.625 & 0.115 & 6640.63 \\
\hline 63 & 12 & 0.06 & 12 & 1.25 & 0.321 & 6692.91 \\
\hline 64 & 8 & 0.06 & 8 & 0.3125 & 0.059 & 1220.1 \\
\hline 65 & 12 & 0.02 & 12 & 1.25 & 0.242 & 2542.37 \\
\hline 66 & 4 & 0.06 & 12 & 1.25 & $*$ & $*$ \\
\hline 67 & 12 & 0.06 & 12 & 0.625 & 0.123 & 2927.67 \\
\hline 68 & 4 & 0.04 & 12 & 0.3125 & 0.066 & 1437.43 \\
\hline 69 & 12 & 0.04 & 8 & 0.625 & 0.064 & 1372.69 \\
\hline 70 & 12 & 0.04 & 24 & 1.25 & 0.603 & 9568.48 \\
\hline 71 & 8 & 0.04 & 8 & 0.3125 & 0.024 & 869.516 \\
\hline 72 & 8 & 0.04 & 8 & 0.625 & 0.051 & 1553.93 \\
\hline 73 & 4 & 0.04 & 12 & 1.25 & 0.155 & 5736.78 \\
\hline 74 & 12 & 0.02 & 24 & 0.625 & 0.104 & 2193.86 \\
\hline 75 & 8 & 0.02 & 12 & 0.625 & 0.057 & 1243.5 \\
\hline 76 & 8 & 0.06 & 12 & 0.625 & 0.09 & 3298.84 \\
\hline 77 & 8 & 0.06 & 12 & 1.25 & 0.34 & 7299.62 \\
\hline 78 & 4 & 0.06 & 24 & 1.25 & $*$ & * \\
\hline 79 & 8 & 0.04 & 12 & 1.25 & 0.326 & 5193.48 \\
\hline 80 & 8 & 0.04 & 8 & 1.25 & 0.202 & 3456.85 \\
\hline 81 & 12 & 0.06 & 12 & 0.3125 & 0.09 & 1683.54 \\
\hline
\end{tabular}

*Unable to collect data due to tool failure. 